\title{
O perfil da mulher portadora de HIV/AIDS e sua adesão à terapêutica antirretroviral"
}

\author{
THE PROFILE OF WOMEN WITH HIVIAIDS AND THEIR ADHERENCE TO THE \\ ANTIRETROVIRAL THERAPY

\begin{abstract}
PERFIL DE LA MUJER PORTADORA DE HIVISIDA Y SU ADHESIÓN A LA TERAPÉUTICA
\end{abstract} \\ ANTIRRETROVIRAL
}

\section{Gabriela Felix', Maria Filomena Ceolim²}

\begin{abstract}
RESUMO
Esse trabalho teve como objetivos caracterizar o perfil sociodemográfico e clínico, os comportamentos em saúde, crenças e atitudes sobre a doença e o tratamento de mulheres com HIV/AIDS atendidas no serviço ambulatorial de um hospital universitário do interior de São Paulo, bem como identificar fatores que interferem na adesão à terapêutica antirretroviral. Os sujeitos do estudo foram 60 mulheres acompanhadas no serviço. Os dados foram colhidos por meio de entrevista semiestruturada. As mulheres tinham idade média de 39,8 (desvio padrão 9,1) anos, baixa escolaridade, condições socioeconômicas insatisfatórias e mantinham relacionamento estável. A relação heterossexual foi a forma mais frequente de infecção; 55\% das mulheres já abandonaram o tratamento e alegavam como principais motivos os esquemas terapêuticos impostos, os efeitos colaterais dos antirretrovirais, o enfrentamento psicológico da doença e o pesar iminente da morte; 35\% delas não atingiram critérios de adesão considerando-se o uso de $95 \%$ da terapêutica antirretroviral prescrita.
\end{abstract}

\section{DESCRITORES}

HIV

Síndrome de Imunodeficiência Adquirida Mulheres

Terapia antirretroviral de alta atividade Cuidados de enfermagem

\begin{abstract}
The objectives of this study were to characterize the sociodemographic and clinical profiles, health behaviors, beliefs and attitudes towards the disease and treatment of women with HIV/AIDS, outpatients of a university hospital located in the interior of São Paulo state, and to identify the factors that affect their adherence to antiretroviral therapy. The participants were 60 female outpatients of the referred service. The data were collected through semi-structured interviews. The women's mean age was 39.8 (standard deviation of 9.1) years; most of the women had a low education level, lived in deprived socioeconomic conditions, and were in a stable relationship. The most frequent form of infection was through a heterosexual relationship; 55\% of the women had abandoned treatment, and their main reasons were the imposed therapeutic schemes, the side effects of antiretroviral drugs, coping with the disease, and the perspective of imminent death; $35 \%$ did not meet the adherence criteria, considered as taking $95 \%$ of the prescribed antiretroviral therapy.
\end{abstract}

\section{DESCRIPTORS}

HIV

Acquired Immunodeficiency Syndrome

Women

Antiretroviral therapy, highly active

Nursing care

\begin{abstract}
RESUMEN
Trabajo que objetivó caracterizar el perfil sociodemográfico y clínico, el comportamiento en salud, creencias y actitudes sobre la enfermedad y el tratamiento de mujeres con HIV/SIDA atendidas en servicio ambulatorio de hospital universitario del interior de São Paulo, así como identificar factores que interfieren en la adhesión a la terapéutica antirretroviral. Los sujetos del estudio fueron 60 mujeres atendidas en el servicio. Datos recolectados mediante entrevista semiestructurada. Las mujeres tenían un promedio etario de 39,8 (desvío estándar 9,1), baja escolaridad, condiciones socioeconómicas insatisfactorias, y mantenían relación estable. La relación heterosexual fue la forma más frecuente de infección; $55 \%$ de las mujeres ya abandonaron el tratamiento, alegando como motivos principales los esquemas terapéuticos impuestos, los efectos colaterales de los antirretrovirales, el enfrentamiento psicológico de la enfermedad y el dolor inminente de la muerte; $35 \%$ de ellas no alcanzaron criterios de adhesión, considerándose el uso del $95 \%$ de la terapéutica antirretroviral prescripta.
\end{abstract}

\section{DESCRIPTORES}

VIH

Síndrome de Inmunodeficiencia Adquirida Terapia antirretroviral altamente activa Mujeres

Atención de enfermería

\footnotetext{
* Extraído do trabalho de conclusão de curso "O perfil da mulher portadora de HIV/aids e sua adesão à terapêutica antirretroviral ", Curso de Graduação em Enfermagem da Faculdade de Ciências Médicas da Universidade Estadual de Campinas, 2010. ${ }^{1}$ Enfermeira pela da Faculdade de Ciências Médicas da Universidade Estadual de Campinas. Campinas, SP, Brasil. gabsfelix@gmail.com²Enfermeira. Livre-docente. Professora Associada do Departamento de Enfermagem da Faculdade de Ciências Médicas da Universidade Estadual de Campinas. Campinas, SP, Brasil. fceolim@fcm.unicamp.br
} 


\section{INTRODUÇÃO}

A epidemia global da aids (do inglês, Acquired Immune Deficiency Syndrome - Síndrome da Imunodeficiência Adquirida) teve seus primeiros casos relatados na literatura no início de 1981, nos Estados Unidos. Duas décadas após, o número de doentes e infectados pelo HIV em todo o mundo já ultrapassava 40 milhões, e a epidemia continua crescendo, principalmente nos países mais pobres ${ }^{(1)}$.

No Brasil, foram realizados 592.914 diagnósticos de 1980 até junho de 2010, dos quais 385.818 foram referentes ao sexo masculino e 207.080, ao feminino. A razão de sexo (masculino/feminino) vem diminuindo ao longo da série histórica, passando de 15,1:1 em 1986 para 1,5:1 em 2002 , proporção que se mantém atualmente ${ }^{(2)}$. A epidemia de aids é um grande problema de saúde pública no Brasil e, como em outros países, constata-se que a velocidade de crescimento está maior em mulheres do que em homens, ${ }^{(3-4)}$ comprovando a feminização da epidemia. No século $\mathrm{XXI}$, a aids passa a figurar entre as principais causas de mortalidade de mulheres em idade fértil, demonstrando a magnitude com que tem atingido a população feminina ${ }^{(4)}$. A partir disso, revela-se a necessidade de melhor explorar a temática, pois se trata de um segmento com especificidades que o distinguem da população masculina e que apresenta desvantagens relativas à prevenção, ao controle e tratamento da infecção(5).

Um dos problemas descritos com relação à prevenção das doenças sexualmente transmissíveis e da aids entre as mulheres é o uso do preservativo, algo de difícil negociação nas relações entre homens e muIheres, principalmente quando se trata de relações estreitas e duradouras. Em uma relação estável entre um casal, exigir o uso de preservativos com outra finalidade que não a contracepção implica, para a mulher, em riscos que perpassam desde questões ligadas à afetividade, como a quebra de confiança entre o casal, até as questões culturais, como os rótulos atribuídos às mulheres que mostram conhecimento e iniciativa na esfera sexual e mesmo o risco de perder o apoio financeiro do parceiro, caso dependa dele ${ }^{(3)}$. Uma pesquisa nacional confirma o fato de as mulheres usarem anticoncepcionais orais no casamento e atribuírem a importância ao uso da camisinha, quando se trata de prevenção de doenças sexualmente transmissíveis, somente para pessoas que não possuam um relacionamento fixo, ou para quando um homem casado trai a esposa. Aqui, elas distinguem dois universos: o da mulher dentro de casa e o das mulheres da rua ${ }^{(6)}$.

Por outro lado, é possível que a mulher, ao assumir uma multiplicidade de papéis - filha, esposa, mãe, dona de casa e/ou trabalhadora -, muitas vezes relegue a um segundo plano o cuidado com o próprio corpo e com a própria saúde ${ }^{(5)}$. Nesse contexto destaca-se, por sua importância, outra problemática observada nessa população: a adesão ao tratamento de doenças como a aids. Esse aspecto constitui um desafio ao profissional de saúde pelas implicações que extrapolam a pessoa doente e atingem também a família e a comunidade ${ }^{(7)}$.

O Brasil foi um dos primeiros países em desenvolvimento a garantir o acesso universal e gratuito aos medicamentos antirretrovirais no Sistema Único de Saúde (SUS) a partir de $1996^{(8)}$. Essa terapêutica tem imposto benefícios consideráveis ao seu usuário, como prolongamento de sobrevida, melhoria da qualidade de vida, diminuição de episódios mórbidos e do número e frequência de internações; porém, requer perfeita adesão ${ }^{(9)}$. Estudos indicam que a eficácia do tratamento, expressa nos níveis de supressão viral, exige que o uso do esquema terapêutico seja igual ou superior a $95 \%$ das doses prescritas. A adesão insatisfatória pode associar-se ao desenvolvimento de resistência viral(10).

Alguns fatores identificados como limitantes ou impeditivos da adesão à consulta e à terapêutica são relacionados às características do indivíduo, da doença e do seu tratamento, à relação entre a equipe de saúde e o indivíduo, à inserção social e também a fatores como distância geográfica do serviço de saúde, dificuldades no acesso à consulta (insuficiência de médicos, grande número de indivíduos atendidos, numerosas listas de espera) e grande intervalo de tempo entre as consultas ${ }^{(9)}$.

Os profissionais e a equipe de saúde podem se valer da compreensão dos fatores que dificultam e que facilitam a adesão, mediante a descrição por parte do próprio paciente de suas experiências, atitudes e crenças sobre a doença e o tratamento, para ajudá-lo a compreender a importância da terapia antirretroviral e melhorar o comportamento de adesão $^{(10)}$. A compreensão desses aspectos limitantes à adesão é o primeiro passo para o seu manejo e superação e, na prática cotidiana dos serviços de saúde, as dificuldades de adesão devem ser identificadas e compreendidas caso a caso ${ }^{(10)}$.

Considerando-se o perfil emergente da doença, as perspectivas de progressivo aumento da população feminina infectada com HIV/aids e, principalmente, a importância da manutenção adequada do tratamento antirretroviral para o controle de sua evolução, faz-se importante obter subsídios que permitam planejar a assistência de enfermagem buscando otimizar a adesão a esses medicamentos.

Visando esse propósito, os objetivos desse trabalho foram caracterizar o perfil sócio-demográfico e clínico, com- 
portamentos em saúde, crenças e atitudes sobre a doença e o tratamento de mulheres com HIV/aids em seguimento no serviço de assistência especializada de um hospital universitário do interior de São Paulo, e identificar fatores que interferem na adesão à terapêutica antirretroviral.

\section{MÉTODO}

Tipo de estudo: estudo transversal e descritivo, com abordagem quantitativa.

Campo de estudo: desenvolvido em hospital universitário do interior do estado de São Paulo, na Unidade de Hospital Dia em HIV/Aids (HD/Aids) e na Unidade de Pesquisa Clínica em HIV/Aids (UPC) da disciplina de Moléstias Infecciosas e Parasitárias.

Sujeitos: trata-se de uma amostra não probabilística constituída por 60 mulheres que atendiam aos seguintes critérios de inclusão: idade igual ou superior a 18 anos; condições clínicas e cognitivas para responder às perguntas dos instrumentos do estudo; participação voluntária, assinando Termo de Consentimento Livre e Esclarecido (TCLE) após receber orientações sobre a pesquisa; em acompanhamento ambulatorial pela equipe de saúde dos campos de estudo. $O$ tamanho da amostra foi estabelecido de acordo com o período de coleta de dados, fixado de maio a julho de 2010.

Aspectos éticos: 0 estudo foi autorizado pelos responsáveis pelos campos de pesquisa e aprovado pelo Comitê de Ética em Pesquisa da instituição das autoras (parecer no 079/2010 de 23/03/2010) encontrando-se em conformidade com a Resolução CNS/MS 196/96.

Coleta de dados: As entrevistas foram realizadas em local que garantia privacidade para sua condução. As muIheres foram convidadas a participar segundo a ordem de chegada ao serviço. Os dados foram coletados com os instrumentos: Instrumento de Coleta de Dados - Ambulatório de Adesão ao Tratamento/aids ${ }^{(7)}$; Caracterização de uma população com 50 anos ou mais portadora de HIV/ aids ${ }^{(11)}$. Os autores de ambos os instrumentos autorizaram seu uso neste estudo.

O Instrumento de Coleta de Dados - Ambulatório de Adesão ao Tratamento/aids é um formulário de entrevista semi-estruturado que visa mensurar a adesão aos antirretrovirais e os fatores que a facilitam ou dificultam. Originalmente construído e validado no $\mathrm{Brasi}^{\left({ }^{(7)}\right.}$, foi adaptado e é utilizado rotineiramente com pacientes do Hospital Dia em aids da instituição.

O instrumento Caracterização de uma população com 50 anos ou mais portadora do HIV/aids é um formulário construído e validado no Brasil com o objetivo de caracterizar sociodemográfica e clinicamente a população de 50 anos ou mais com HIV/aids; identificar comportamentos em saúde, crenças e atitudes sobre a doença e o trata- mento a que estão submetidos ${ }^{(11)}$. Foi utilizado neste estudo sem necessidade de adaptação.

Análise dos dados: Os dados foram digitados em um banco de dados no programa Excel for Windows ${ }^{\circledR}$ e analisados com estatística descritiva, em números absolutos e percentuais para as variáveis categóricas e medidas de tendência central, posição e dispersão para as variáveis numéricas.

\section{RESULTADOS}

As mulheres estudadas eram, na sua maioria, de raça branca $(66,7 \%)$, predominando entre elas a união estável $(46,6 \%)$ e a religião católica (55\%). Dentre todas as religiões citadas, $65 \%$ referiram ser praticantes. A idade variou entre 19 e 64 anos, com média de 39,8 (desvio padrão 9,1) anos. Entre elas $91,7 \%$ referiram ter filhos e $70 \%$ tinham entre um e dois filhos. Quanto à escolaridade, 98,3\% afirmaram ter estudado, sendo que $48,3 \%$ referiram ter cursado ensino fundamental incompleto, com 7,5 (desvio padrão 3,6 ) anos de estudo, em média. A maioria não tinha vínculo empregatício ou trabalho informal, sendo, portanto, do lar (61,7\%), seguindo-se ocupações de baixa qualificação, como faxineiras e cozinheiras, entre outras (25,3\%). A ocupação do tempo dava-se principalmente em atividades no lar (74,9\%), seguindo-se as atividades no trabalho (25\%).

A maior parte $(80 \%)$ referiu morar com duas a quatro pessoas, com média de 3,5 (desvio padrão 1,6), sendo que $65 \%$ afirmaram não serem responsáveis pelo sustento da casa; $35 \%$ não sabiam de quantos salários mínimos era a renda mensal da família; $51,6 \%$ referiam renda familiar de um a três salários mínimos. Dentre as mulheres, $75 \%$ afirmaram receber ajuda nos momentos de dificuldade financeira, principalmente dos pais e familiares $(46,6 \%)$.

O quadro clínico das mulheres foi avaliado segundo dois parâmetros laboratoriais: carga viral e contagem de linfócitos $\mathrm{CD} 4+$, em dois momentos distintos, ou seja, no início do tratamento e à época da entrevista. No início do tratamento, a maioria das mulheres apresentava contagem de CD4+ inferior a 200 células $/ \mathrm{mm}^{3}$ (38,7\%), porém com o decorrer do mesmo, $41,7 \%$ das entrevistadas passaram a apresentar contagem de CD4+ entre 200-500 células $/ \mathrm{mm}^{3}$. A carga viral acompanhou essas características, pois, no início do tratamento, $48,3 \%$ das mulheres tinham carga viral entre $50-50.000$ cópias $/ \mathrm{mm}^{3}$ enquanto que, na contagem atual, $60 \%$ apresentaram carga viral inferior a 50 cópias $/ \mathrm{mm}^{3}$. Desta população, $76,6 \%$ já apresentaram alguma doença oportunista relacionada ao HIV/ aids anteriormente, sendo mais frequentes pneumonia por Pneumocystis carinii, monilíase e tuberculose $(31,8 \%$, $28,4 \%$ e $27,2 \%$ respectivamente).

Com relação ao estadiamento da doença, $50 \%$ se encontravam na classificação SIDA C3 ${ }^{(12)}$ e $95 \%$ faziam uso de 
medicamentos antirretrovirais. Os medicamentos antirretrovirais mais utilizados eram lamivudina $(52,63 \%)$, tenofovir $(35,08 \%$ ) e zidovudina (33,3\%), sendo que $46,7 \%$ tomavam de três a quatro antiretrovirais por dia, variando de três a dez comprimidos ao dia. Segundo a maioria (76,7\%), precisavam interromper suas atividades duas vezes ao dia para tomar todos os comprimidos prescritos.

Das 60 mulheres entrevistadas, 41,7\% apresentavam, atualmente, alguma doença oportunista relacionada ao HIV/aids e $58,3 \%$ apresentavam outras doenças. Entre as doenças oportunistas destacavam-se a neurotoxoplasmose $(15,2 \%)$, seguida da tuberculose pulmonar e neurotuberculose $(8,5 \%)$ e, entre as demais doenças apresentadas, destacavam-se os distúrbios hormonais $(23,3 \%)$ e cardiovasculares (15\%).

Observou-se que $75 \%$ das mulheres referiam doenças oportunistas tratadas, enquanto que a proporção de muIheres com registro dessas doenças no prontuário foi de $76 \%$. As doenças oportunistas atuais foram relatadas por $23,3 \%$, porém os registros no prontuário apontavam que uma proporção de $41,7 \%$ estava em tratamento de alguma doença oportunista.

Com relação aos hábitos de vida, a grande maioria afirmou não fazer uso de bebida alcoólica (78,3\%), cigarros $(73,3 \%)$ ou drogas $(98,3 \%)$. Com relação à atividade sexual, $66,7 \%$ referiam serem ativas e todas eram heterossexuais. Dentre as sexualmente ativas, $61,7 \%$ relataram ter parceiro fixo, com quem se relacionavam há 10,4 anos (desvio padrão 7,1 ) e $48,3 \%$ viviam sob o mesmo teto. Apenas uma $(1,7 \%)$ referiu relacionar-se com mais de uma pessoa atualmente, e $61,7 \%$ relatavam o uso de proteção nas relações sexuais, sendo unânime o uso de preservativo pelo parceiro. Dentre as que se protegiam, $16,7 \%$ encontravam dificuldades, e a principal queixa era que o parceiro não gostava de utilizar a proteção.

A respeito da vida sexual antes do diagnóstico, 13,3\% relataram manter relações sexuais com mais de uma pessoa e $85 \%$ não faziam uso de proteção. As principais razões explicitadas foram a confiança no parceiro, associada à despreocupação quanto à necessidade de usar proteção $(83,5 \%)$ e a falta de conhecimento sobre o vírus e a doença $(15,1 \%)$.

Referente às crenças e as atitudes sobre a doença e o tratamento, $51,7 \%$ das entrevistadas alegaram que sua rotina de vida mudou em função do tratamento para HIV/ Aids e $31,7 \%$ consideravam seu tratamento difícil de ser realizado. Apesar de acharem difícil o esquema terapêutico prescrito, incluindo o número de medicamentos, suas formas e horários, $65 \%$ negavam precisar de ajuda com as medicações, conseguindo lembrar-se de todos os detaIhes do tratamento.

Quando questionadas sobre há quanto tempo sabiam do diagnóstico, as respostas variaram desde menos de um ano até 20 anos, com média foi de 9,4 (desvio padrão 4,3) anos. A principal forma por meio da qual ficaram sabendo de seu diagnóstico foram os exames de sorologia, realizados após o relacionamento sexual com uma pessoa infectada por HIV (28,3\%) ou durante uma internação hospitalar devido a uma complicação de saúde (25\%). O início do tratamento deu-se há mais de nove anos segundo $45 \%$ das entrevistadas, e $88,3 \%$ afirmaram ter melhorado das complicações de saúde após o início do mesmo.

A principal forma de aquisição da infecção, de acordo com as mulheres, foi por relação sexual (90\%), e $5 \%$ adquiriram por meio de transmissão vertical. A maioria (75\%) referiu complicações anteriores devido ao HIV/aids e proporção semelhante (76\%) negou a presença de complicações relacionadas ao vírus atualmente.

Os efeitos colaterais da terapia antirretroviral foram relatados por $55 \%$, sendo as principais queixas os sintomas gastrintestinais $(46,7 \%)$ e o mal-estar associado à sensação de fraqueza ( $25 \%$ ).

Uma proporção expressiva (55\%) alegava ter abandonado o tratamento em algum período desde o início do mesmo, sendo as principais causas a depressão e a expectativa de morte iminente $(20,2 \%)$, as reações adversas $(18,4 \%)$ e os relatos de não suportar o tratamento, associados ao esquecimento de tomar os comprimidos nos horários corretos $(15,2 \%)$. Todas apresentaram piora em seu estado de saúde com o abandono. A ocorrência de uma doença oportunista $(26,7 \%)$ e a preocupação de deixar seus filhos órfãos e não vê-los crescer $(20,1 \%)$ foram apontadas como os principais responsáveis pelo retorno ao tratamento. Ainda sobre o abandono do tratamento, $35 \%$ afirmam que o fizeram apenas uma vez, porém ao analisar o prontuário destas pacientes verificou-se, em $15 \%$ dos casos, discrepância entre esse discurso e o registro nos prontuários, em que o número de abandonos era duas vezes superior ao relatado.

As informações oferecidas pela equipe de saúde foram consideradas suficientes para esclarecimento por $98,3 \%$ das participantes.

Destaca-se que, dentre as entrevistadas, 35\% não atingiram adesão, avaliada pela ingestão de $95 \%$ da terapêutica antirretroviral prescrita, nos três dias anteriores à entrevista.

\section{DISCUSSÃO}

Atualmente a epidemiologia da aids no Brasil caracteriza-se pela heterosexualização, feminilização, faixa etária jovem, baixo nível de escolaridade e pauperização da doença ${ }^{(13)}$. Neste estudo, o perfil sócio-demográfico das mulheres com HIV/aids acompanha a evolução das características da população atingida pela doença no Brasil. Segundo o Boletim Epidemiológico 2010 do Ministério da Saúde ${ }^{(2)}$ a taxa de incidência de casos de aids notificados no SINAN foi maior na faixa etária de 30 a 39 anos, con- 
gruente com a média de idade neste estudo (39,8 anos). Com relação à maternidade, $91,7 \%$ referiam ter filhos e $70 \%$ tinham entre um e dois filhos, semelhante a uma pesquisa realizada com mulheres vivendo com HIV/aids em São Paulo, em que a média foi de 1,8 filhos $^{(14)}$.

$\mathrm{O}$ aumento da proporção de casos de aids em pessoas com menor escolaridade tem sido denominado pauperização, considerando-se nesse contexto a escolaridade como marcador da situação socioeconômica ${ }^{(15)}$. Neste estudo destacou-se a grande proporção de mulheres com ensino fundamental incompleto e sem vínculo empregatício, a maioria do lar ou empregadas em serviços de baixa qualificação, o que está de acordo com outros estudos ${ }^{(15-16)}$. A baixa escolaridade pode implicar em prejuízos à adesão, interferindo inclusive na compreensão da terapêutica, devido às dificuldades na interpretação das informações oferecidas pela equipe de saúde e no reconhecimento da importância de realizar o tratamento corretamente. $\mathrm{O}$ trabalho remunerado e as condições sócio-econômicas são primordiais para a manutenção da adesão ao tratamento para a mulher com HIV/aids. As dimensões sócio-econômicas interferem no viver com HIV/aids, pois as medicações exigem alimentação de boa qualidade, ir às consultas de rotina demanda tempo, bem como recursos financeiros para transporte, medicações extras e manutenção do $\operatorname{lar}^{(17)}$.

Além do nível de instrução e da ocupação, a renda também está entre os indicadores mais importantes para mensurar o nível sócio-econômico associado à saúde. Mais da metade da população estudada referiu uma renda familiar de um a três salários mínimos e $75 \%$ afirmam receber ajuda em momentos de dificuldade financeira, principalmente de familiares ${ }^{(13)}$.

Entre as mulheres que participaram deste estudo, predominou a união estável $(46,6 \%)$, como em outras pesquisas sobre a mulher com HIV/aids ${ }^{(14-15)}$. A maioria das entrevistadas mantinha ativa a vida sexual e afetiva e, entre estas, $61,7 \%$ referiam que o parceiro fazia uso do preservativo masculino quando mantinham relações sexuais. Contudo, aquelas que se protegiam revelavam a necessidade de negociação cotidiana com o parceiro, que em geral não gostava de utilizar o preservativo. 0 relato dessas mulheres mostra sua posição vulnerável à infecção pelo HIV, pois encontram dificuldades em negociar o uso do preservativo, discutir fidelidade e mesmo abandonar as relações que as mesmas consideravam que as colocavam em risco de contaminação. A situação da contaminação remete à condição feminina, referindo-se à submissão e dependência de seus parceiros e ao amor como elementos integrantes da identidade feminina, impeditivos de ações preventivas ${ }^{(15)}$. A principal causa de aquisição do vírus, neste estudo, foi a relação sexual, semelhante a outras pesquisas ${ }^{(15-18)}$. A relação heterossexual é a forma de transmissão que mais tem contribuído para a feminização da epidemia em nosso país ${ }^{(15)}$. Os comportamentos preventivos, mesmo conhecidos pelos sujeitos, não são praticados na maioria das situações (vulnerabilidade individual). Desigualdades de renda e gê- nero interferem tanto na aquisição de informações como na tomada de decisões para a prevenção da aids (vulnerabilidade social). Papéis masculinos e femininos estabelecidos culturalmente interferem substancialmente nas decisões sobre prevenção do HIV/aids escolhidas pelos indivíduos (vulnerabilidade cultural) ${ }^{(18)}$.

Ao falarem de sua vida antes da descoberta do HIV/aids, quase todas revelaram que não faziam uso de proteção em suas relações sexuais, pois as mantinham com parceiro fixo no qual confiavam e, consequentemente, não se preocupavam quanto à necessidade de usar proteção. Os relatos sugerem que estas mulheres não dominam o uso dos meios de proteção, pois entendem que a não utilização de preservativos pode significar a confiança no seu parceiro e a certeza, pelo menos para elas, de um relacionamento monogâmico e o seu inteiro compromisso com a relação a dois. Para estas mulheres o diagnóstico revelou-se como uma grande surpresa, principalmente porque muitas delas adquiriram a aids de seus parceiros fixos, quando, para elas, o relacionamento conjugal estava construído sobre a forte segurança do confiar e acreditar no outro.

Em estudo realizado sobre a infecção entre casais ${ }^{(19)}$ a maioria das entrevistadas vinculavam a confiança a uma forma de relacionar-se com o parceiro, fazendo com que se encontrassem, de alguma forma, seguras em relação aos risco de infecção pelo HIV. O preservativo passou a ser visto como forma de prevenção da gravidez indesejável e seu uso era abandonado quando a construção do vínculo da confiança se estabelecia entre o casal. Acredita-se que, quando a relação é estabelecida, os corpos tornam-se um só e os riscos desaparecem, e que os parceiros são pessoas seguras e confiáveis ${ }^{(19)}$.

Observa-se que, neste estudo, as mulheres parecem não considerar que possuem comportamentos compatíveis com os denominados comportamentos de risco para aquisição de HIV/aids, sendo estes associados a prostituição, promiscuidade e relações extraconjugais ${ }^{(18)}$. A grande maioria referiu não fazer uso de álcool, cigarros e drogas ilícitas, bem como manter relacionamento conjugal estável, ou seja, contradizem o perfil tido como de risco para as mulheres no imaginário social do $\mathrm{Brasi}^{(3)}$. Como evidenciado por outros autores, a percepção de risco dessas mulheres é muito pequena, visto que a imagem conjugal expressa a cultura em que estão inseridas no que diz respeito aos papéis de gênero e hierarquização da relação afetivo-sexual. Isso pode explicar a restrição da adoção de comportamentos preventivos, tornando-as vulneráveis à infecção por HIV ${ }^{(18)}$. Para estas mulheres que não se identificam com os grupos de risco, a aids continuaria sendo uma "doença dos outros"(20). Para elas é como se houvesse dois tipos de aids: a aids dos outros e a aids das pessoas comuns. A primeira é vista como tendo sido adquirida de forma voluntária, resultado de um comportamento irresponsável. A segunda é considerada involuntária, consequência da natureza masculina e do desempenho de um papel social, o de esposa. 
Com relação à caracterização do quadro clínico das pacientes, no início do acompanhamento, 48,3\% apresentaram uma carga viral entre 50 a 50.000 cópias $/ \mathrm{mm}^{3}$ e $38,7 \%$, um TCD4+ menor 200 células $/ \mathrm{mm}^{3}$. Sabe-se que número de linfócitos TCD4+ no sangue periférico atualmente é considerado o principal marcador de dano imunológico causado pela infecção do HIV e um importante indicador de progressão para aids. Essas mulheres, consequentemente, apresentavam risco elevado de evoluir com infecções oportunistas. Entre as doenças definidoras de aids ${ }^{(12)}$ incluem-se condições indicativas de imunodepressão severa, principalmente da imunidade celular, além da contagem de linfócitos TCD4+ inferior a 200 células/mm3, independente da presença de sintomas. Grande parte das mulheres acompanhadas por esta pesquisa $(76,6 \%)$ já teve no mínimo uma complicação de saúde relacionada ao HIV/aids, representada por uma doença oportunista. O diagnóstico de infecções oportunistas e de manifestações clínicas mais comuns entre as pacientes está de acordo com uma pesquisa em que a distribuição observada foi pneumonia por Pneumocystis carinii $(31,8 \%)$, moníliase $(28,4 \%)$ e tuberculose $(27,2 \%)^{(21)}$.

No presente estudo nota-se que o uso da terapêutica antirretroviral era necessário para praticamente toda a população estudada (95\%). O aumento da sobrevida de pessoas soropositivas ao HIV/aids, bem como a redução da incidência de doenças oportunistas tem sido amplamente demonstrados com a utilização de drogas antirretrovirais, o que constitui um importante resultado a favor desses medicamentos. Apesar do grande benefício gerado por esta terapêutica e reconhecido pelas pessoas com HIV, restam ainda muitas dificuldades a serem superadas. Uma delas é a adesão ao tratamento medicamentoso ${ }^{(22)}$.

Ao analisar as crenças e atitudes sobre a doença e o tratamento, $51,7 \%$ das entrevistadas alegaram que sua rotina de vida mudou em função do tratamento para HIV/ aids, o que está de acordo com outro estudo(20) em que as mulheres relataram perdas e mudanças predominantemente negativas (perda da alegria, sentimento de estranheza, medo, isolamento social por preconceito, a rotina de consultas e frequente coleta de exames) com a descoberta da soropositividade.

Outro fato que chama a atenção nesta pesquisa é que $31,7 \%$ das mulheres entrevistadas consideravam seu tratamento difícil de ser realizado, apontando o número de medicamentos prescritos, sua forma de ingestão e horários. Sabe-se que o esquema terapêutico prescrito está associado a não adesão, mesmo quando o medicamento é fornecido. Esse é um dos principais fatores que interferem no tratamento com antirretrovirais, pois os esquemas terapêuticos, normalmente, são complicados e exigem um grande empenho por parte do cliente, que precisa adaptar sua alimentação, horários e ritmo diário para cumprir o tratamento ${ }^{(22)}$.

O grande avanço dos medicamentos antirretrovirais foi uma conquista para os pacientes com HIV/aids, porém um dos principais dificultadores da adesão à terapêutica com esses fármacos ainda são os frequentes efeitos colaterais que podem causar. Tais efeitos foram relatados por $55 \%$ das mulheres entrevistadas neste estudo, assim como observado em outras pesquisas ${ }^{(16,21-22)}$. Destaca-se que muitas das entrevistadas conseguiam associar cada efeito colateral a determinado medicamento antirretroviral e revelavam deixar de tomá-los quando se sentiam pior com o uso dos mesmos. As principais queixas relatadas foram os sintomas gastrintestinais (náuseas, vômitos, diarréias), seguido de mal-estar associado à sensação de fraqueza, sendo também, os principais sintomas apresentados na literatura sobre o assunto.

Atenção especial merece o abandono do tratamento, relatado por $55 \%$ das muIheres em algum período desde o início do mesmo. As causas relatadas para tal atitude referem-se, principalmente, à depressão e à expectativa de morte iminente, seguido das reações adversas associadas aos antirretrovirais. A perspectiva iminente de morte é um dos principais aspectos para não adesão ao tratamento. Embora enfrentem os efeitos colaterais e o preconceito, o desânimo surge também diante da perspectiva de que o tratamento oferecido ainda não traz a cura e pode apenas prolongar a vida ${ }^{(22)}$. Diante dos relatos dessas mulheres, pode-se perceber sua fragilidade e sua impotência diante da doença para a qual, a despeito de todo o conhecimento científico já adquirido, ainda não foi obtida a cura. $O$ significado construído na vida dessas mulheres parece carregado de desesperança, medo e pensamentos que limitam os projetos de vida futuros, visto que enfrentar os desgastes físicos e sociais que a doença implica pode não valer a pena, uma vez que a cura definitiva não será alcançada ${ }^{(22)}$.

Os relatos enfocam o fato de ter que tomar a medicação para o resto de suas vidas para continuarem a viver, sendo, portanto, considerados os grandes mediadores de suas vidas.

Com relação ao abandono muitas apontaram o fato de não suportarem o tratamento, associado ao esquecimento de tomar os comprimidos nos horários corretos. Como em outro estudo ${ }^{(21)}$ o principal motivo relatado para a falha terapêutica foi o esquecimento de tomar os medicamentos. Considerando-se que o esquecimento pode representar uma forma de rejeição, ressalta-se a necessidade de buscar mecanismos que ajudem os pacientes a se engajarem no tratamento. 
Como esperado, todas as entrevistadas que abandonaram o tratamento revelaram piora em seu estado geral de saúde e, segundo relataram, o surgimento de uma doença oportunista, bem como o apoio do parceiro, familiares e filhos as fizeram voltar ao tratamento. A conviç̧ão nos efeitos positivos do tratamento parece levar os sujeitos a acreditar que a terapia é a única maneira de continuar a viver. Embora existam fatores que dificultam a adesão, há aqueles que motivam as pessoas a aderirem ao tratamento medicamentoso ${ }^{(22)}$. Um destes, importante para a adesão, revela-se o apoio e a aceitação por parte das pessoas mais próximas. $\mathrm{O}$ isolamento decorrente da resistência em aceitar a própria situação ou o fato de que o ambiente social seja preconceituoso, junto com a depressão, a falta de apoio e a ausência de alguém com quem trocar experiências dificultam a adesão ${ }^{(20)}$.

A preocupação com os filhos e a vontade de vê-los crescer foi um fator de destaque entre aqueles apontados pelas mulheres como importantes para a adesão ao tratamento antirretroviral. Como também observado por outros autores $^{(17)}$ as mulheres referiram buscar forças na maternidade para manterem a adesão. A mulher deixa, muitas vezes, de se preocupar com a morte em seu contexto individual e passa a se preocupar com a morte em função dos filhos, pois sabe que os mesmos dependem dela para sobreviver e sente-se na obrigação de protegê-los contra o preconceito que possam vir a sofrer frente à visão que persiste na sociedade quanto aos estereótipos relacionados à aids.

Enfim, por meio da questão sobre a quantidade de medicamentos tomados diariamente nos três dias que antecederam a entrevista e o confronto posterior dos prontuários com a prescrição médica dos antirretrovirais, observou-se que $35 \%$ das mulheres entrevistadas nesta pesquisa não atingiram a adesão considerada satisfatória, de ingestão mínima de $95 \%$ dos medicamentos prescritos, ou seja, níveis próximos ao ideal para supressão da replicação viral e contenção da multiplicação de cepas resistentes aos antirretrovirais. Este achado está de acordo com outro estudo(21) em que $34 \%$ dos pacientes relataram níveis inferiores a $95 \%$ de adesão a terapêutica antirretroviral.

\section{CONCLUSÃO}

Os resultados deste estudo, realizado com mulheres com HIV/aids atendidas em serviço ambulatorial de um hospital universitário do interior de São Paulo, permitiram concluir que eram mulheres jovens $(39,8$ anos em média), vivendo em união estável e com filhos; tinham baixa escolaridade e ausência de vínculo empregatício, ou exerciam ocupações de baixa qualificação; predominava entre elas a classificação SIDA C3 e a maior parte fazia uso de medicamentos antirretrovirais; eram sexualmente ativas, mas nem todas usavam proteção nas rela- ções sexuais; a principal forma de aquisição da infecção foi por relação sexual heterossexual; para a maioria, a rotina de vida mudou em função do tratamento para HIV/aids e este é difícil de ser realizado; metade delas abandonou o tratamento pelo menos uma vez, sendo as principais causas a depressão e a expectativa de morte iminente, reações adversas aos antirretrovirais e relatos de não suportar o tratamento; o abandono trouxe piora do estado de saúde e a ocorrência de uma doença oportunista foi responsável pelo retorno ao tratamento; quase todas referiam que as informações oferecidas pela equipe de saúde foram suficientes para seu esclarecimento, porém 35\% não atingiram adesão, avaliada pela ingestão de $95 \%$ da terapêutica antirretroviral prescrita, nos três dias anteriores à entrevista.

Destaca-se, nesta pesquisa, que as mulheres estão se contaminando com o vírus dentro dos relacionamentos conjugais e, portanto, vê-se a necessidade de campanhas e orientações direcionadas a casais em união estável, nas quais devem ser considerados os valores envolvidos na adoção das práticas de prevenção.

A adesão ao tratamento mostrou-se algo conquistado diariamente e a adesão efetiva parece ser obtida apenas a partir do momento em que são reconhecidas a necessidade do tratamento e a sua condição como pessoa com HIV/aids, para continuar a viver. Além disso, salientou-se nesta pesquisa a importância atribuída pelas mulheres ao desejo de cuidar dos seus filhos e vê-los crescer, apontando esse fator como um motivo relevante para manter a adesão ao tratamento. Esse é um aspecto que merece investigação mais detalhada em futuros estudos.

Outro fator a destacar é que a maioria das mulheres sentia-se esclarecida quanto às explicações oferecidas pelos serviços em que o estudo foi realizado, o que mostra a importância do apoio dos profissionais envolvidos. Neste contexto ressalta-se o papel do enfermeiro na equipe multiprofissional, visto que este profissional assiste a pessoa com aids de maneira direta e deve sempre estar atento para orientar adequadamente e investigar os principais fatores associados à não-adesão. É fundamental explicar os procedimentos em linguagem simples e objetiva buscando, em conjunto com os pacientes, formas mais toleráveis para uso dos esquemas de antirretrovirais e para que não esqueçam de tomá-los. É primordial ajudá-los a entender que a aids é considerada uma doença crônica e que somente com a ajuda desta terapêutica poderão viver com qualidade. Entretanto, é vital que o enfermeiro mantenha-se atento aos fatores envolvidos na adesão ao tratamento de cada paciente de maneira singular e tente resgatar na família das mulheres o apoio, visto que estas se sentem mais preparadas em enfrentar toda a discriminação da doença com o acolhimento e apoio de familiares e amigos. Dessa forma, acredita-se que a construção da adesão poderá ser mais bem sucedida. 


\section{REFERÊNCIAS}

1. Ribeiro AF, Madalasso G, Veras MASM, Guerra MAT, Lemos RRG. Epidemiologia - HIV. In: Veronesi RF, editor. Tratado de infectologia. 3a ed. São Paulo: Atheneu; 2005. p. 118-27.

2. Brasil. Ministério da Saúde; Departamento de DST, AIDS e Hepatites Virais. Dados epidemiológicos de DST, HIV/aids. Boletim Epidemiológico Aids [Internet]. 2010 dez. [citado 2011 abr. 20]. Disponível em: http://www.aids.gov.br/publicacao/ boletim-epidemiologico-2010

3. Santos NJS, Buchalla CM, Fillipe EV, Bugamelli L, Garcia S, Paiva V. Mulheres HIV positivas, reprodução e sexualidade. Rev Saúde Pública. 2002;36(4 Supl):12-23.

4. Santos NJS, Tayra A, Silva SR, Buchalla CM, Laurenti R. A aids no Estado de São Paulo: as mudanças no perfil da epidemia e perspectivas da vigilância epidemiológica. Rev Bras Epidemiol. 2002;5(2):286-310.

5. Takahashi RF, Shima H, Souza M. Mulher e Aids: perfil de uma população infectada e reflexões sobre suas implicações sociais. Rev Latino Am Enferm. 1998;6(5):59-65.

6. Giacomozzi Al, Camargo BV. Eu confio no meu marido: estudo da representação social de mulheres com parceiro fixo sobre prevenção da Aids. Psicol Teor Prat. 2004; 6(1):31-44.

7. Colombrini MRC, Dela Coleta MF, Lopes MHBM. Fatores de risco para a não adesão ao tratamento com terapia antiretroviral altamente eficaz. Rev Esc Enferm USP. 2008;42(3):490-5.

8. Dourado I, Veras MASM, Barreira D, Brito AM de. Tendências da epidemia de Aids no Brasil após a terapia antirretroviral. Rev Saúde Pública. 2006;40 Supl:9-17.

9. Gir E, Vaichulonis CG, Oliveira MD. Adesão à terapêutica antirretroviral por indivíduos assistidos em uma instituição no interior paulista. Rev Latino Am Enferm. 2005;13(5):634-41.

10. Brasil. Ministério da Saúde; Secretaria de Vigilância em Saúde. Programa Nacional de DST e Aids. Manual de adesão ao tratamento para pessoas vivendo com HIV e aids. Brasília; 2008.

11. Lima TC, Gallani MCBJ, Freitas MIP. Validação do conteúdo de instrumento para caracterizar pessoas maiores de 50 anos portadoras Virus da Imunodeficência Humana/ Síndrome da Imunodeficiência Adquirida. Acta Paul Enferm. 2012;25(1):4-10.
12. Centers for Disease Control and Prevention (CDC). Revised Classification System for HIV Infection and Expanded Surveillance Case Definition for AIDS Among Adolescents and Adults. MMWR [Internet]. 1992 [acesso em 2010 Out 10]; 41(RR-17): [aprox. 17p.]. Disponível em: http://www.cdc. gov/mmwr/preview/mmwrhtml/00018871.htm

13. Andreolli A. As pessoas que vivem com HIV/Aids: uma revisão da literatura científica [monografia]. Porto Alegre: Universidade Federal do Rio Grande do Sul; 2008.

14. Paiva V, Latorre MR, Gravato N, Lacerda R. Sexualidade de mulheres vivendo com HIV/AIDS em São Paulo. Cad Saúde Pública. 2002;18(6):1609-20.

15. Gabriel R, Barbosa DA, Vianna LAC. Perfil epidemiológico dos clientes com HIV/AIDS da Unidade Ambulatorial de Hospital Escola de grande porte-município de São Paulo. Rev Latino Am Enferm. 2005;13(4):509-13.

16. Lignani Junior L, Greco DB, Carneiro M. Avaliação da aderência aos antirretrovirais em pacientes com infecção pelo HIV/ Aids. Rev Saúde Pública. 2001;35(6):495-501.

17. Costa DAM, Zago MMF, Medeiros M. Experiência da adesão ao tratamento entre mulheres com Vírus da Imunodeficiência Humana/Síndrome da Imunodeficiência Adquirida. Acta Paul Enferm. 2009;22(5):631-7.

18. Maia C, Guilhem D, Freitas D. Vulnerabilidade ao HIV/Aids de pessoas heterossexuais casadas ou em união estável. Rev Saúde Pública. 2008;42(2):242-8.

19. Oltramari LC, Otto LS. Conjugalidade e Aids: um estudo sobre infecção entre casais. Psicol Soc. 2006;18(3):55-61.

20. Cardoso G, Arruda A. As representações sociais da soropositividade entre as mulheres e a adesão ao tratamento. Cad Saúde Coletiva. 2003;11(2):183-99.

21. Carvalho CV, Duarte DB, Merchán-Hamann E, Bicudo E, Laguardia J. Determinantes da aderência à terapia antirretroviral combinada em Brasília, Distrito Federal, Brasil, 19992000. Cad Saúde Pública. 2003;19(2):593-604.

22. Teixeira MG, Silva GA. A representação do portador do vírus da imunodeficiência humana sobre o tratamento com os antirretrovirais. Rev Esc Enferm USP. 2008; 42(4):729-36. 